\title{
Analysis and Design of Mobile-Based Waste Management Applications Prototype Methods
}

\author{
Muhammad Arief Kusmawardani ${ }^{1 *}$, Aulia Lismaya ${ }^{2}$, Muhammad Rivai ${ }^{3}$, Raden Allam Ramzy \\ Fauzan $^{4}$ and R. A. E. Virgana Targa Sapanji ${ }^{5}$
}

Information System Department, University of Widyatama, Bandung, Indonesia arief.kusmawardani@widyatama.ac.id ${ }^{1 *}$, aulia.lismaya@widyatama.ac.id ${ }^{2}$, muhammad.rivai@widyatama.ac.id ${ }^{3}$ allam.ramzy@widyatama.ac.id ${ }^{4}$, rae.virgana@widyatama.ac.id ${ }^{5}$

Article History: Received:11 January 2021; Accepted: 27 February 2021; Published online: 5 April 2021

\begin{abstract}
As the time goes by, a rapid growth of human population would eventually lead to the increase of daily waste. A lack of awareness of the community to dispose of waste properly might further harm the surrounding environment. Many people have limited knowledge as to where the garbage is dumped. In regard to that case, an Android-based waste management application system is designed. The prototype method is built for the system. This application is meant to carry out waste disposal transactions that can be accessed on Android. Hopefully, this application could increase user's interest in disposing the waste and able to increase public insight in distinguishing organic and non-organic waste. The purpose of this research is to keep the community environment clean and healthy.
\end{abstract}

Keywords: Mobile application, waste, prototype, user interface

\section{Introduction}

As the times develop and the human population increases, the need for human consumption will also increase. Humans will not feel satisfied with the needs that are considered sufficient but will continue to feel less and the goal is no longer for the necessities of life but to fulfill an excessive lifestyle, therefore there will be a lot of things that are wasted for nothing which eventually becomes trash. Waste is the residue of various daily activities carried out by humans or natural processes in the form of solid or semi-solid in the form of biodegradable or non-biodegradable substances which are considered useless and disposed of into the environment (Slamet, 2002).

Garbage is still a problem faced by the whole world, especially in Indonesia, because the increase in waste is not matched by proper and environmentally friendly waste management. Moreover, the lack of public concern for the waste that continues to increase and is not environmentally friendly is evidenced by the large number of people littering, and based on data on waste produced by Indonesia, it produces approximately 64 million tons each year.

With the increasing development of increasingly sophisticated technology, we can use it to solve problems that occur today, especially regarding this waste management. One of them is using a mobile. With this problem, the researcher will design a system to pick up the garbage with an Android-based application and this research will also create a user experience and user interface for a mobile-based waste management application for a solution to dispose of waste so that waste is not disposed of carelessly which can damage the environment and even people get points. profit if you use this waste disposal service or transaction.

\section{Literature Review}

\subsection{Mobile application}

According to Buyens (2001), mobile applications are derived from the application and mobile of the words. The application means application, application, use. In terms of application is a ready-to-use program designed to perform a function for users or other applications and can also be used by the intended target, while mobile itself can be interpreted as moving from one place to another quickly.

Vijay Kumar Velu (2016) explains that one of the technologies that will develop in an interesting future in the mobile application space is the development of a mobile application that runs on an Android device, where the application can listen to signals from beacons in the physical world and react accordingly.

From the two meanings above, it can be concluded that a mobile application is an application that can be accessed on a mobile device and can also be connected to the internet so that in its use the mobile application can be used anywhere and anytime. 


\subsection{Waste}

According to the definition of the World Health Organization (WHO) Waste isn't used anymore, not used, not liked, or something that has been discarded derived from human activities that occur on its own (Chandra, 2006)

According to Davis and Conwell (2008) explains that the word solid waste is a word commonly used to describe something that we throw away. If discarded carelessly or left alone, it can damage the environmental ecosystem.

From the two studies above, it can be concluded that waste is something that is no longer used by humans, if the garbage is left alone it can damage the environment around us.

\subsection{User experience}

User Experience relates to what users feel related to ease, comfort, efficiency, and utilization when using a page on a website or application (Naser, 2018).

\subsection{User interface}

In addition to the aesthetic aspects that appear visually, the design of the user interface must be able to convey its function. According to Nielsen's study, usability is the ultimate goal of user interface design. Components that really determine the usability of a design are ease of learning, efficiency, user memory related to application functions after several uses, errors that have been used. And user decisions (Rianingtyas, 2018).

\subsection{Prototype}

Model Prototype is "a process that allows developers to create a software model, this method is good to use if the client cannot provide maximum information about the desired needs (Yurindra 2017).

\section{Research Methodology}

The author uses a research methodology and data collection techniques.

\subsection{Prototype method}

Before a program or application has been released, an initial version of the software design is made for testing to improve the application called a prototype. In the prototype, the design and functions of the menus of the application will be reviewed, and look for deficiencies or weaknesses in the application before being released so that it can be ascertained that the application can run well.

This prototyping method aims to get an overview of the design and application functions that will be built through the design of a prototype application so that if there is a shortage it will be re-evaluated for improving the application.



Figure 1. Prototyping Model by Khosrow-Pour

\subsection{Data collection techniques}

The author performs several data collection techniques namely:

1. Observation.

The author makes direct observations of activities related to the problems taken so that the data obtained is more complete. In this case, the writer made direct observations at Widyatama University.

2. Questionnaire. 
The author collects data through forms containing questions that are submitted in writing to a person or group of people to get answers so that the data obtained is more accurate.

3. Literature Study

This method is used to use studies, books, reports relating to the title appointed as a reference for the author, the information is taken from various existing sources.

\section{Results and Discussion}

In this section, the results of the research and discussion are presented in the form of pictures, graphs, tables, etc. so that readers can understand them in a simple but precise manner.

\subsection{Respondents}

From all the questionnaires that have been distributed. The level of public understanding of waste is still not that great but with the introduction of the waste management application program, this is welcomed by the community and supports the application program to run and develop even better.

\subsection{Needs analysis}

In the analysis and design of information systems for mobile-based waste management applications has 2 types of system requirements, namely functional requirements, and non-functional requirements, for functional needs, which has a relationship with the main function of the application so that each main function will be connected. one another. Meanwhile, non-functional needs function to support the running of the application so that the expected goals in the application can be achieved.

\subsubsection{Analysis of functional requirements}

Functional requirements are requirements that contain a process or a service that will have been provided by the system, as the system will work or react to certain input and how the system responds to a certain situation.

\subsubsection{Analysis of non-functional requirements}

Non-functional requirements are needs that involve the behavioral properties of the system. Non-functional requirements can also be referred to as a service or function offered by the system such as process development limitations, time constraints, standardization, and others. The non-functional requirements include:

1. Hardware

Hardware is a type of hardware that can operate to help applications run and function properly. The following are the minimum hardware specifications required, including:
a. Computer
Processor $\quad: 1.5 \mathrm{GHz}$ dual-core
Ram :2GB DDR3
Hardisk $\quad: 250 \mathrm{~GB}$
Monitor : : 14.0 "LED
b. Mobile
Processor $\quad: 1.40 \mathrm{GHz}$ Octa-core
Ram $\quad: 2 \mathrm{~GB}$

\section{Software}

Software is software that is part of applications on computers and mobile to help applications run and function properly. The software required is, as follows:

a. Microsoft Windows 8 as an operating system on a computer

b. Android or IOS as the mobile operating system

c. Figma as a tool for making prototype applications

\subsection{Display software}

This software display will display a display of the application that has been prototyped using the Figma application. The result of this stage is a mobile-based waste management application prototype.

1. Information Page 1 Application

This page is created to provide information and education to users and the public to always divide and sort the waste to be disposed of based on the type of waste, including when using this service. 


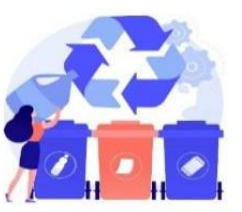

Separate your waste



sending it to us

$\overrightarrow{\text { Next }}$

Figure 2. Information page 1 application

2. Information Page 2 Application

This page is made to provide information and education to users and the public, including when using this application services to select services available in this application based on user needs.

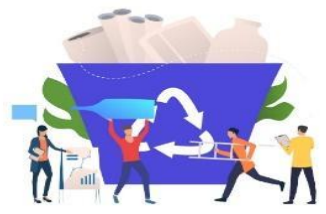

Choose our services

We provide services that help

everyone who manage their waste based on their needs

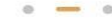

Figure 3. Information page 2 application

\section{Information Page 3 Application}

This page was created to invite users and the public to manage waste to be disposed of to use this service so as not to damage the environment and get benefits in using these services.

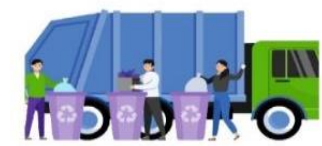

Recycle with us

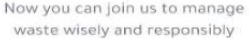

- -



Figure 4. Information page 3 
4. Start

Page This page is created to provide options for users to register if not and login if they have already registered.

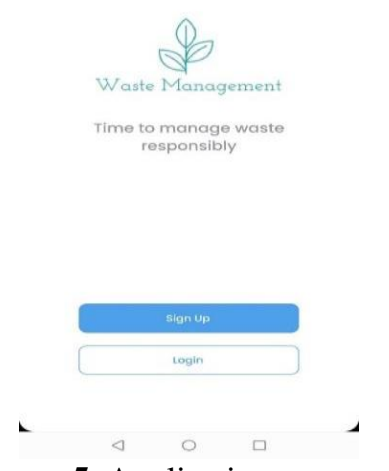

Figure 5. Application start page

\section{Registration} service.

Page This page is made for user registration so that user information is stored and becomes a member of this

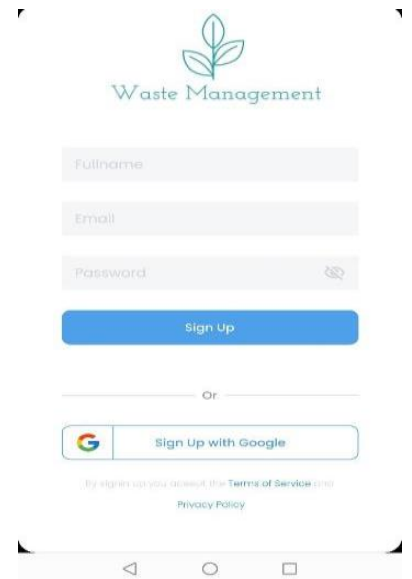

Figure 6. Application registration page

6. Login

Page This page is made to log in to the application if you have registered and become a member of this application service. And so that unauthorized parties cannot access and process data without logging in first.

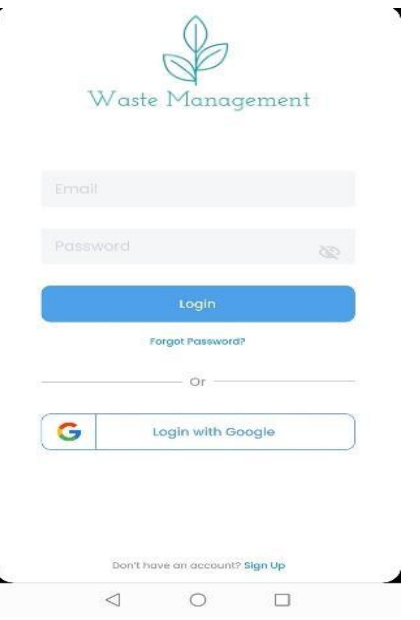

Figure 7. Application login page 


\section{Home}

Page This page is the main page of the application to start accessing the menu provided by this waste management service.

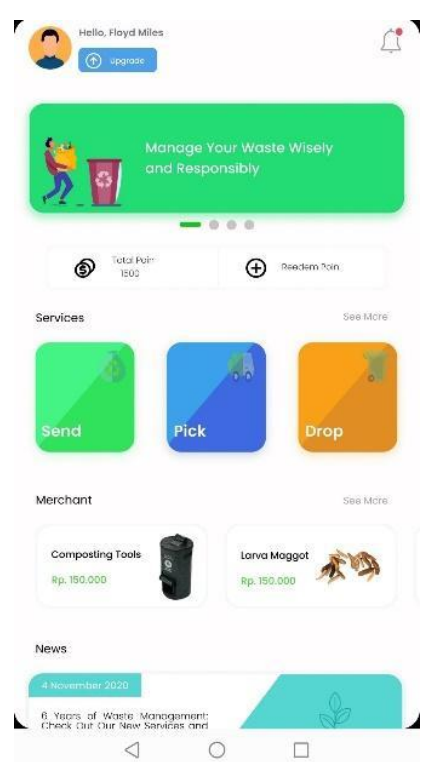

Figure 8. Application home page

\section{Garbage Delivery Page 1 Application}

The delivery menu is a menu where the user sends waste that has been separated according to its type and then the waste will be sent by the user to waste 4 change for garbage disposal through the type of delivery chosen by the user. At the beginning of the delivery menu, the user will be asked to fill in the user's address and delivery destination.

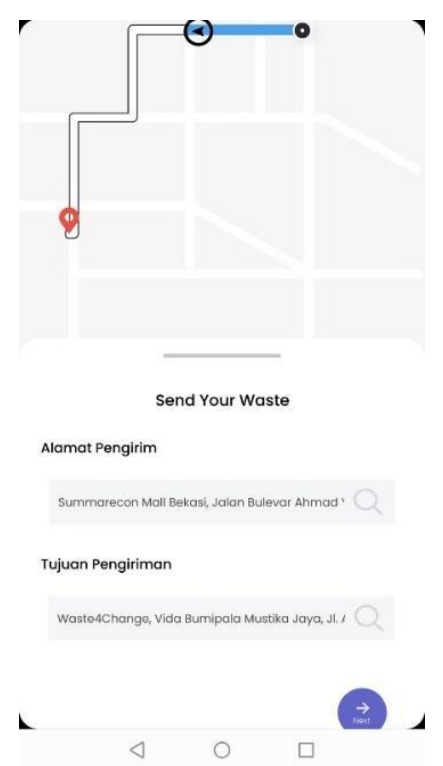

Figure 9. Garbage delivery page 1 application

9. Garbage Delivery Page 2 Application

On the second waste delivery page or the next part, the user will be asked to choose the type of waste and the type of waste delivery. 


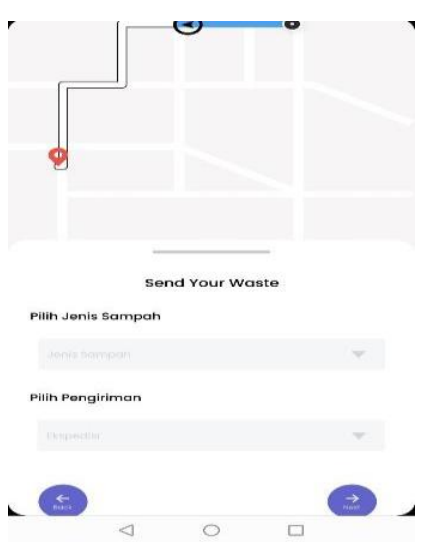

Figure 10. Garbage delivery page 2 application

\section{Garbage Delivery Page 3 Application}

On this page, the user will get an invoice from the admin regarding waste information that will be sent to waste 4 change. After that, In the user is asked to make payment for the delivery service.

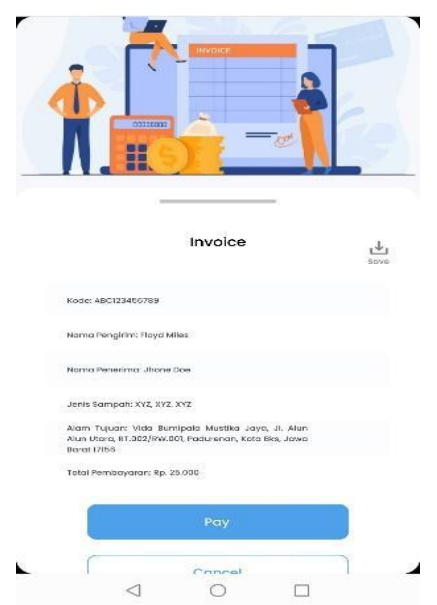

Figure 11. Garbage delivery page 3 application

\section{Garbage Delivery Page 4 Application}

On this page a thank you will appear from waste 4 change for using the services provided to help reduce environmental pollution due to garbage being dumped carelessly and if the user has completed the transaction, then users will get points given by waste 4 change to be exchanged for various kinds of offers provided.

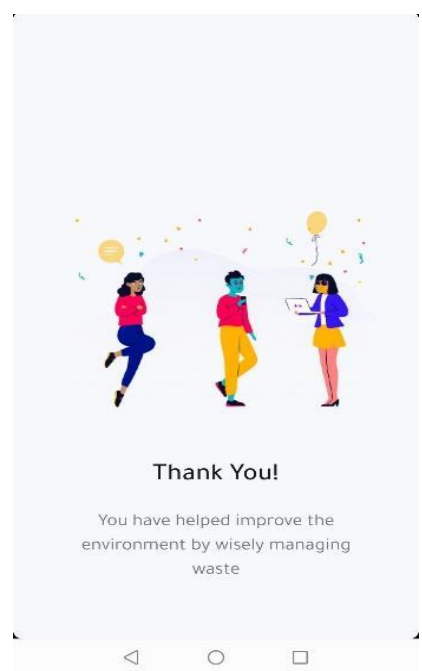

Figure 12. Garbage delivery page 4 application 


\section{Garbage Pick-up Page 1 Application}

The pick-up menu is a menu where the user will dispose of the waste that has been separated according to its type then the user asks for 4 changes to waste to pick up the trash and on this menu is a menu that can be subscribed. At the beginning of the pick-up menu, the user will be asked to fill in the user's address or the garbage pick-up point to be disposed of.



Coverage Area
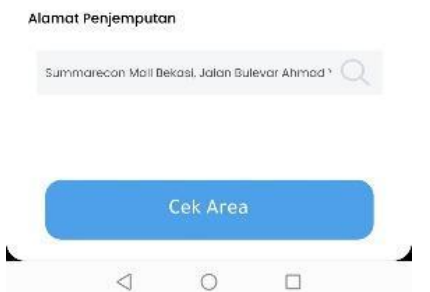

Figure 13. Garbage pick-up page 1 application

\section{Garbage Pick-up Page 2 Application}

The next menu from the garbage pick-up menu, the user will be asked to choose the type of subscription to choose, for the type of subscription waste 4 change gives 3 options, namely a subscription for 3 months, 6 months, and 12 months in which the 12 months subscription will get a payment discount.
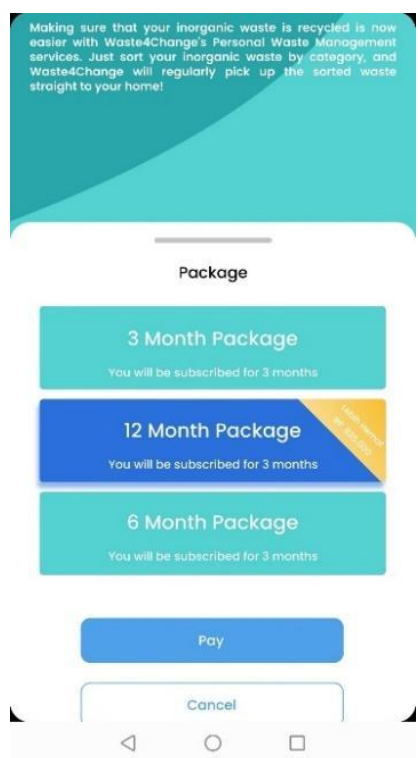

Figure 14. Garbage pick-up page 2 applications

\section{Garbage Pick-up Page 3 Applications}

For the next step, the user will be asked to determine a garbage pick-up schedule that will be sent to waste 4 changes starting from the day and time that it will be picked up every 1 week. 


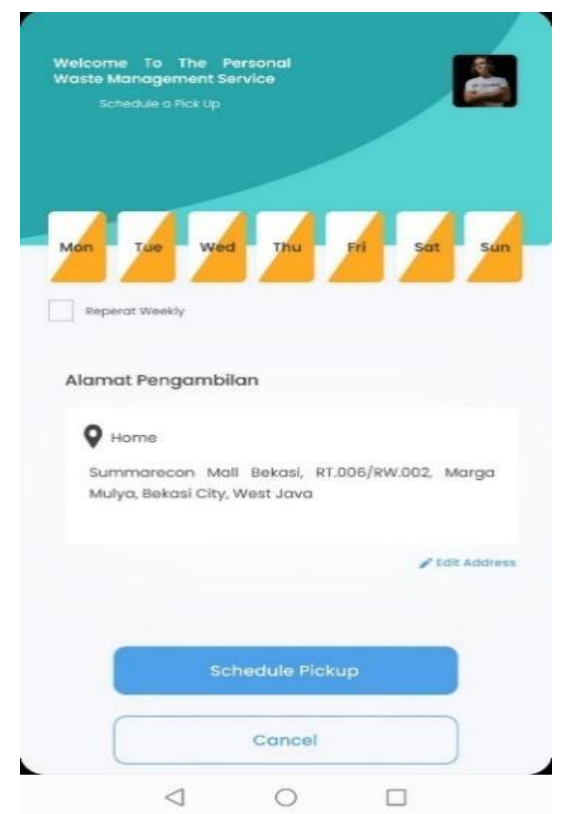

Figure 15. Garbage Pick-up Page 3 Applications

15. Garbage Pick-up Page 4 Applications

On this page, the user will get information about picking up the waste that has been determined but waste 4 change will provide services for the user if he wants to rearrange the next schedule.
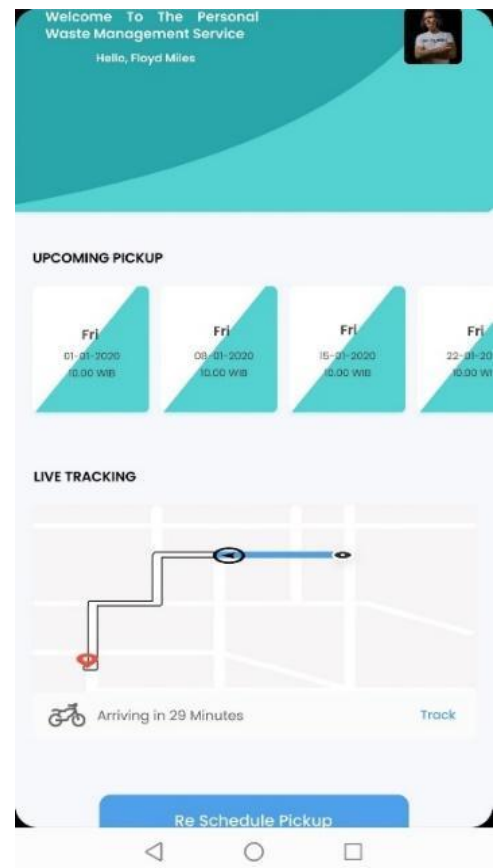

Figure 16. Garbage pickup page 4 Applications

\subsection{Navigation structure design}

The design of this navigation structure has one navigation designed for users where the design consists of several stages as shown below. 


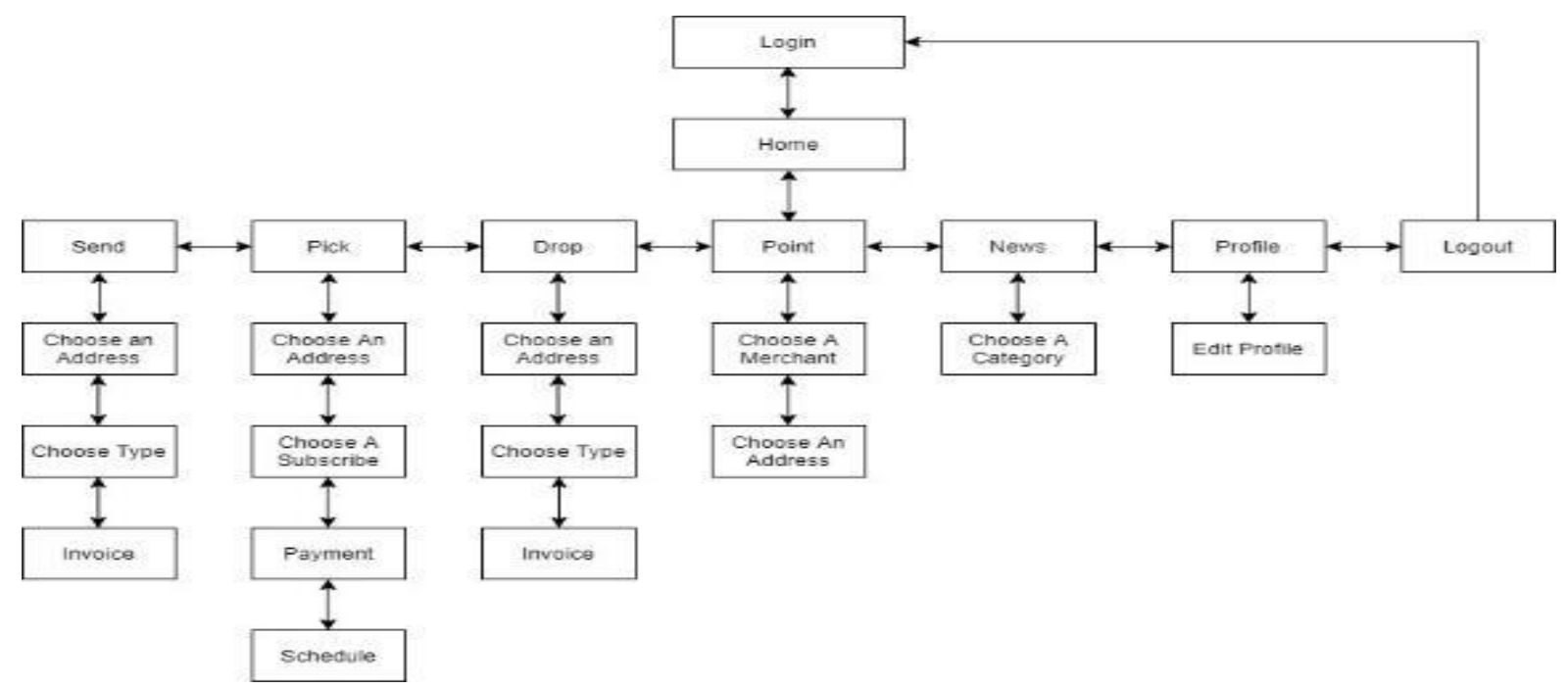

Figure 17. User-level navigation structure

\section{Conclusion}

Some conclusions that the authors can conclude from the previous discussion include the following:

1. Provide a waste disposal service information application design that runs on the system mobile application

2. This application is designed to it makes easier for people to dispose of waste properly and environmentally friendly.

3. This application is designed to be able to help reduce or cope with waste.

4. This mobile-based garbage collection service application is expected to run smoothly and by what was designed earlier.

This application is designed not completely as expected, here are suggestions that can help in designing this application is:

1. It hoped that the design of this application design is more attractive to attract the attention of others

2. The security level of data users It is hoped that security can be guaranteed.

To implement this application, it is expected that it can be used on all devices.

\section{References}

1. Rianingtyas, A. K and Wandari, K. K. (2018). Perancangan user Interface aplikasi mobile sebagai media promosi digital UMKM tour dan travel. Jurnal Sains dan Seni ITS, 7(2), F-118-F123.

2. Yurindra. (2017). Software Engineering. Yogyakarta: Deepublish.

3. Chandra, Budiman. (2016). Pengantar Kesehatan. EGC. Jakarta.

4. Vijay Kumar Velu. (2016). Mobile Application Penetration Testing. Birmingham: PACKT Publishing.

5. Naser, D. A. (2018). Perancangan user interface dan user experience halmana website. DEKAVE: Jurnal Design Komunikasi Visual, 8(1), 1-23

6. McWherter, Jeff and Gowel, Scott. (2012). Professional Mobile Application Development. Indianapolis: John Wiley \& Sons.

7. Panhale, Mahensh. (2016). Beginning Hybrid Mobile Application Development. Springer.

8. Iriana Bakti, Feliza Zubair, Yustikasari, Priyo Subekti. (2020). Android Based Waste Management Information System. Lincoln: Digital Commons. 